\title{
Development of an in vitro drug sensitivity assay for Trichuris muris first-stage larvae
}

\author{
David Wimmersberger ${ }^{1,2}$, Lucienne Tritten ${ }^{1,2}$ and Jennifer Keiser ${ }^{1,2^{*}}$
}

\begin{abstract}
Background: Trichuriasis represents a major public health problem in the developing world and is regarded as a neglected disease. Albendazole and mebendazole, the two drugs of choice against trichuriasis display only moderate cure rates, hence alternative drugs are needed. To identify candidate compounds, in vitro drug sensitivity testing currently relies on the adult Trichuris muris motility assay. The objective of the present study was to develop a simple and cost-effective drug sensitivity assay using Trichuris muris first-stage larvae (L1).

Methods: Several potential triggers that induce hatching of T. muris were studied, including gastrointestinal enzymes, acidic environment and intestinal microflora. Next, optimal culture conditions for T. muris L1 were determined assessing a wide range of culture media. T. muris $L 1$ were incubated in the presence of mebendazole, ivermectin, nitazoxanide, levamisole or oxantel pamoate at $37^{\circ} \mathrm{C}$. The viability of the parasites was evaluated microscopically after 24 hours. The usefulness of fluorescent markers (resazurin, calcein AM, ethidium homodimer-1 or fluorescein-conjugated albumin) in drug sensitivity testing was also assessed.

Results: The established L1 motility assay provided accurate and reproducible drug effect data in vitro. $I C_{50}$ values for oxantel pamoate, levamisole and nitazoxanide were $0.05,1.75$ and $4.43 \mu \mathrm{g} / \mathrm{mL}$, respectively. Mebendazole and ivermectin failed to show any trichuricidal effect on L1. No correlation was found between data from the four fluorescent markers and the comparative motility assay.

Conclusions: The motility assay based on L1 was found suitable for drug sensitivity screening. It is rather simple, cost-effective, time-saving and sustains medium-throughput testing. Furthermore, it greatly reduces the need for the animal host and is therefore more ethical. None of the viability markers assessed in this study were found to be satisfactory.
\end{abstract}

Keywords: Trichuris muris, Nitazoxanide, Levamisole, Oxantel pamoate, In vitro assay, Resazurin, Fluorescein-albumin, Calcein AM, Ethidium homodimer-1

\section{Background}

Human trichuriasis, caused by the gut-dwelling soiltransmitted helminth species Trichuris trichiura, represents a major public health problem in the developing world since an estimated 604-795 million people are infected worldwide [1]. T. trichiura infections are responsible for the loss of 349,000-1,061,000 disability-adjusted life years (DALYs) per year [2]. Particularly affected, school- and preschool-aged children are confronted with the largest morbidity burden [3]. Mild infections are often asymptomatic, however, in severe and chronic infections patients can

\footnotetext{
* Correspondence: jennifer.keiser@unibas.ch

${ }^{1}$ Department of Medical Parasitology and Infection Biology, Swiss Tropical and Public Health Institute, P.O. Box, Basel CH-4002, Switzerland

${ }^{2}$ University of Basel, Basel $\mathrm{CH}-4003$, Switzerland
}

suffer from dysentery, anemia and impairment of physical and mental development [3]. The drugs recommended by the World Health Organization [4], albendazole and mebendazole, have been in use for decades and display only moderate cure rates when administered as single doses [5-7]. Although this has not arisen as a problem yet, potential emergence of drug resistance is of concern $[5,6]$. Thus, there is a need to find novel anthelmintic drugs for the treatment of this disease.

For drug testing purposes, a user-friendly and inexpensive in vitro assay is desirable to accurately determine the drug sensitivity of the worms as a first screen filter. Using the mouse whipworm T. muris [8,9], the current assay of choice is the adult motility assay [10-12]. It is

\section{Biomed Central}


well established and reliable but suffers from significant drawbacks: it is expensive, time-consuming and necessitates the sacrifice of the murine host and therefore, is not suitable for medium- to high-throughput screening in its actual form.

The aim of the present study was to develop a simple, cost-effective and time-saving alternative to the drug sensitivity assay currently in use. After excluding potential hatching triggers such as intestinal enzymes and gastric $\mathrm{pH}$, we exploited the ability of first-stage larvae (L1) to hatch following exposure of T. muris eggs to intestinal bacteria, such as Escherichia coli [13]. Subsequently, optimal culture conditions for L1 were determined and the currently used adult motility assay was adapted to L1. The trichuricidal effects of three standard anthelmintics (mebendazole, ivermectin and levamisole) were studied and compared to two potential alternative drugs (nitazoxanide and oxantel pamoate).

In addition, we assessed four potential viability markers, resazurin (Alamar Blue ${ }^{\circledR}$ ), fluorescein-albumin isothiocyanate conjugate (feeding inhibition assay), calcein acetoxymethyl ester (AM) and ethidium homodimer-1 (both from LIVE/DEAD ${ }^{\circledR}$ cell viability kit).

Resazurin is a colorimetric and fluorescent dye that has been successfully used in in vitro drug sensitivity assays for several parasitic species such as African trypanosomes and more recently for adult $T$. muris [10,14]. The underlying principle of this dye is the enzymatic reduction of the nonfluorescent molecule resazurin to the fluorescent resorufin by viable cells. The feeding inhibition assay has been used to analyze the feeding behavior of Ancylostoma spp. larvae [15-17]. Viable parasites might ingest medium containing the fluorescent molecule (bovine albumin conjugated to fluorescein), which allows the discrimination from dead parasites by microscopical observation of the stained intestinal tract of the worms [12,17]. Finally, we assessed the two-compound LIVE/DEAD ${ }^{\circledR}$ cell viability assay which is designed to dye viable as well as dead mammalian cells and has been used in Leishmania research $[18,19]$. The kit consists of two different dyes: the green-fluorescent calcein AM indicates intracellular esterase activity and thus stains live cells and the red-fluorescent ethidium homodimer-1 (EthD-1) binds to DNA of dead cells presenting a disrupted plasma membrane.

\section{Methods}

\section{Drugs, chemicals and media}

Ivermectin and mebendazole were purchased from SigmaAldrich (Buchs, Switzerland). Levamisole and oxantel pamoate were purchased from Fluka (Buchs, Switzerland). Nitazoxanide was obtained from Laboratoria Wolfs (Zwijndrecht, Belgium). Drug stocks were made in 100\% DMSO (dimethyl sulfoxide, Fluka, Buchs, Switzerland) at a concentration of $10 \mathrm{mg} / \mathrm{mL}$ and stored at $4^{\circ} \mathrm{C}$ pending use.
Resazurin (resazurin sodium salt, $125 \mathrm{mg} / \mathrm{L}$ ), amphotericin B $(250 \mu \mathrm{g} / \mathrm{mL})$, fluorescein-albumin isothiocyanate conjugate lipase (from porcine pancreas), Luria Broth $(25 \mathrm{~g} / \mathrm{L})$, penicillin-streptomycin (10,000 units penicillin + $10 \mathrm{mg} / \mathrm{mL}$ streptomycin) and glucose (anhydrous, 96\%) were purchased from Sigma-Aldrich (Buchs, Switzerland). Bile salts, ciprofloxacin and pepsin (from porcine gastric mucosa) were purchased from Fluka (Buchs, Switzerland). Dulbecco's modified eagle medium (DMEM), Hanks' balanced salt solution (HBSS), Medium 199, Minimum essential medium (MEM) and RPMI 1640 were purchased from Gibco (Basel, Switzerland). Fetal calf serum (FCS) was obtained from Connectorate (Dietikon, Switzerland). LIVE/DEAD ${ }^{\circledR}$ cell viability kit (L-3224) was purchased from Invitrogen (Carlsbad, CA, USA). RPMI medium was prepared using 10.44 g RPMI 1640, $5 \mathrm{~g}$ albumax H (Gibco), 5.94 g HEPES (Sigma-Aldrich) and $2.1 \mathrm{~g}$ sodium bicarbonate (Sigma-Aldrich) in $1 \mathrm{~L}$ deionized water.

\section{Parasites and bacteria}

The life cycle of T. muris is maintained at the Swiss TPH since 2010 as described elsewhere [10]. Briefly, unembryonated eggs released in the feces of infected mice were isolated and purified through flotation with saturated $\mathrm{NaCl}$ (359 $\mathrm{g} / \mathrm{l}$ in deionized water) and cultured in tap water at room temperature for at least eight weeks. Embryonation of eggs was monitored microscopically.

Escherichia coli stem BL-21 was ordered from New England Biolabs (Ipswich, MA, USA). The bacteria were stored in Luria Broth (LB) medium and $30 \%$ glycerin at $-80^{\circ} \mathrm{C}$. To provide bacteria for the hatching process, a pipette tip of the frozen $E$. coli suspension was dipped in LB medium $(25 \mathrm{~g} / \mathrm{L})$ and incubated for 12 to 24 hours at $37^{\circ} \mathrm{C}$.

\section{In vitro studies \\ Hatching}

Several potential triggers of the hatching process of T. muris larvae mimicking the intestinal environment were studied. In all experiments eggs were evaluated microscopically (magnification: 40x) after incubation in the presence of the trigger candidate.

Enzymes T. muris egg suspensions were incubated together with the gastric enzyme pepsin $(3.2 \mathrm{~g} / \mathrm{L} ; \mathrm{pH}: 2)$ or the intestinal enzyme lipase ( $20 \mathrm{~g} / \mathrm{L} ; \mathrm{pH}$ : 7.94; coenzyme: bile salts) at $37^{\circ} \mathrm{C}$ for up to 24 hours. The combination of the two enzymes was studied, too, incubating eggs first in the presence of lipase $(20 \mathrm{~g} / \mathrm{mL})$ for 4 hours at $37^{\circ} \mathrm{C}$ and subsequently adding pepsin $(1.6 \mathrm{~g} / \mathrm{mL})$ for another 24 hours of incubation at $37^{\circ} \mathrm{C}$. Each of these experiments was performed twice independently. 
Acidic conditions T. muris eggs were exposed to $0.9 \%$ $\mathrm{NaCl}$ solution with acidic $\mathrm{pH}$ values of $1,1.5,2,2.5$ and 3 at $37^{\circ} \mathrm{C}$ mimicking the mouse stomach conditions [20]. The experiment was performed twice independently.

Exposure to intestinal bacteria T. muris eggs $(1200 / \mathrm{mL})$ were incubated in RPMI medium (containing $12.5 \mu \mathrm{g} / \mathrm{mL}$ amphotericin B, 500 units $/ \mathrm{mL}$ penicillin, $500 \mu \mathrm{g} / \mathrm{mL}$ streptomycin) in the presence of viable E. coli $\left(10^{7}-10^{8}\right.$ cells $/ \mathrm{mL}$ ) at $37^{\circ} \mathrm{C}$ for 4 hours. Bacterial concentration was determined by optical density measurement at $600 \mathrm{~nm}$ using the formula: OD $\times 5 \times 10^{8}=$ bacterial cells $/ \mathrm{mL}$. The hatching rate, or proportion of hatched larvae in each well, was determined microscopically after 4 hours (magnification: 40x).

\section{Optimal culture conditions}

The viability of $T$. muris L1 was tested in 5 different liquid culture media (RPMI, MEM, DMEM, Medium 199 and HBSS). All media contained $12.5 \mu \mathrm{g} / \mathrm{mL}$ amphotericin B, 500 units $/ \mathrm{mL}$ penicillin and $500 \mu \mathrm{g} / \mathrm{mL}$ streptomycin. Survival rates of the larvae were evaluated microscopically after 24,48 and 72 hours of incubation at $37^{\circ} \mathrm{C}$ following stimulation of the larvae with hot tap water $\left(\approx 70^{\circ} \mathrm{C}\right)$. Motile L1 were considered as viable and immotile L1 as dead. The addition of a supplement to the basic RPMI medium namely $20 \mathrm{~g} / \mathrm{L}$ glucose or 5\% FCS was also assessed. This experiment was performed twice in triplicate for each medium with an average of $30 \mathrm{~L} 1$ per well.

Finally, incubation of $\mathrm{L} 1$ at $37^{\circ} \mathrm{C}$ was compared to room temperature (approximately $24^{\circ} \mathrm{C}$ ). The survival rates of the newly hatched larvae in RPMI medium were examined microscopically after 24, 48, 72, 96 and 120 hours. This experiment was conducted twice in triplicate using approximately 40 worms per well.

\section{Motility assay}

The assay methodology was adapted from the assays described for hookworm and Strongyloides spp. [21] and for adult T. muris [10-12]. Mebendazole, levamisole, ivermectin, nitazoxanide and oxantel pamoate were tested at concentrations of 1,10 and $50 \mu \mathrm{g} / \mathrm{mL}$. Oxantel pamoate was additionally tested at concentrations of 0.1 and $0.01 \mu \mathrm{g} / \mathrm{mL}$. Wells containing parasites exposed to $0.5 \%$ DMSO served as controls. The assay was performed in 96-well plates containing approximately 25 worms per well in a total volume of $100 \mu \mathrm{L}(50 \mu \mathrm{L}$ containing $\mathrm{L} 1+50$ $\mu \mathrm{L}$ drug solution). The well plates were incubated for 24 hours at $37^{\circ} \mathrm{C}$. The motility was then analyzed by stimulating the parasites with hot tap water $\left(\approx 70^{\circ} \mathrm{C}\right)$, using a light microscope (magnification: 40x). A binary scale was used to qualify viability, discriminating live from dead larvae: "0" = no sign of motion = dead and "1" = motion observed $=$ alive. The percentage of dead larvae was established for each well. For each drug and concentration, the assay was conducted in 5 wells, three times independently.

\section{Viability marker assays}

Resazurin assay Twenty $\mu \mathrm{L}$ of resazurin were added to wells containing $100 \mu \mathrm{L}$ of T. muris L1 (approximately 50 per well) and/or E. coli suspensions (medium: RPMI 1640 containing $12.5 \mu \mathrm{g} / \mathrm{mL}$ amphotericin $\mathrm{B}, 500$ units/ $\mathrm{mL}$ penicillin and $500 \mu \mathrm{g} / \mathrm{mL}$ streptomycin). The trichuricidal effect of nitazoxanide was assessed and compared to live controls (viable parasites exposed to $0.5 \%$ DMSO) and larvae killed with $70 \%$ ethanol. Fluorescent emission was measured at $560 \mathrm{~nm}$ (excitation) and $590 \mathrm{~nm}$ (emission) after 12, 24, 36 and 48 hours using a spectrofluorometer (SpectraMax, Gemini XS, Molecular Devices, UK). The antibiotic ciprofloxacin $(500 \mu \mathrm{g} / \mathrm{mL})$ was used to eliminate bacterial contamination of the medium after completion of hatching. The experiment was repeated three times.

Feeding inhibition assay One hundred $\mu \mathrm{L}$ of a $1 \mathrm{mg} / \mathrm{mL}$ fluorescein-albumin isothiocyanate conjugate solution (solubilized in RPMI 1640) were added to wells containing $100 \mu \mathrm{L}$ of $T$. muris $\mathrm{L} 1$ (approximately 50 larvae per well) in RPMI 1640 (containing $12.5 \mu \mathrm{g} / \mathrm{mL}$ amphotericin B, 500 units $/ \mathrm{mL}$ penicillin, $500 \mu \mathrm{g} / \mathrm{mL}$ streptomycin and $500 \mu \mathrm{g} / \mathrm{mL}$ ciprofloxacin). The well plate was incubated at $37^{\circ} \mathrm{C}$ and after 3 hours the larvae were centrifuged $(14,000 \mathrm{rpm})$ and washed three times with phosphate buffered saline (PBS). The larvae were analyzed after 3 and 24 hours using an inverted fluorescence microscope (Carl Zeiss, Germany, magnification: 100-200x, excitation: 450-490 nm, emission: $520 \mathrm{~nm}$ ) [12]. Emissions from motile larvae were compared to those from immotile larvae. The experiment was conducted twice independently.

LIVE/DEAD ${ }^{\circledR}$ cell viability assay Newly hatched $T$. muris L1 were incubated at different concentrations (from 25 to 500 parasites per well) at $37^{\circ} \mathrm{C}$ in $100 \mu \mathrm{L}$ RPMI 1640 (containing $12.5 \mu \mathrm{g} / \mathrm{mL}$ amphotericin B, 500 units $/ \mathrm{mL}$ penicillin, $500 \mu \mathrm{g} / \mathrm{mL}$ streptomycin and $500 \mu \mathrm{g} /$ $\mathrm{mL}$ ciprofloxacin). After 16 hours, $100 \mu \mathrm{L}$ of a calcein AM/ ethidium homodimer-1 solution $(8 \mu \mathrm{M}$ EthD-1 and $4 \mu \mathrm{M}$ calcein AM solubilized in RPMI 1640) were added to each well. The plate was analyzed after 30 minutes, 1, 2, 3, 4 and 24 hours using a spectrofluorometer (SpectraMax, Gemini XS, Molecular Devices, UK; calcein AM: excitation: $485 \mathrm{~nm}$, emission: $525 \mathrm{~nm}$; EthD-1: excitation: $525 \mathrm{~nm}$, emission: $645 \mathrm{~nm}$ ). The emission values were adjusted to the background noise defined as the average signal produced by wells containing E. coli only. Emissions from motile larvae were compared to those from immotile 
larvae. Using $100 \mathrm{~L} 1$ per well, an assay was performed with nitazoxanide and levamisole at concentrations of 1, 10 and $50 \mu \mathrm{g} / \mathrm{mL}$ (0.5\% DMSO served as a control sample). Samples were analyzed using a fluorescence microscope using texas red- (excitation: $577 \mathrm{~nm}$; emission: $620 \mathrm{~nm}$ ) and L5-filters (excitation: $480 \mathrm{~nm}$; emission: $527 \mathrm{~nm}$ ). The assay was performed three times independently.

\section{Statistical analysis}

All data sets were analyzed by OpenOffice (Apache Software Foundation, 2010). Means ( \pm standard deviations) of motilities and emissions were calculated from repeated tests. Motility differences between drug treatments and controls were tested for significance using the Fisher's exact test in R ( R 2.12.0, R Development Core Team, 2012). $\mathrm{IC}_{50}$ values of the motility assay were calculated based on median effect principle using the CompuSyn software (TingChao Chou and Nick Martin; ComboSyn, Inc., 2007) [22]. These were defined as the concentration of a drug required to decrease the mean worm motility to $50 \%$. The $r$ value is the linear correlation coefficient of the median-effect plot. It illustrates the goodness of fit, and thus the accuracy of the $\mathrm{IC}_{50}$ value.

\section{Results \\ Hatching \\ Enzymes}

After 24 hours in a pepsin solution (3.2 g/L; pH: 2), embryonated $T$. muris eggs were phenotypically still intact. No digestive degradation of the eggshell could be observed, nor had hatching been induced. Embryonated T. muris eggs exposed to lipase (20 g/L; pH: 7.94), were found intact after 24 hours and no hatching had taken place. Similarly, the addition of pepsin $(1.6 \mathrm{~g} / \mathrm{L})$ after 4 hours to the lipase solution did not show any effect after 24 hours of incubation at $37^{\circ} \mathrm{C}$.

\section{Acidic conditions}

No alteration of the eggshell could be observed microscopically after 2 hours of incubation at any $\mathrm{pH}$ value studied at $37^{\circ} \mathrm{C}$ and no larva was observed to hatch.

\section{Intestinal microflora}

Exposing T. muris eggs to an E. coli suspension induced hatching of approximately $70 \%$ of the eggs after 2-4 hours of incubation at $37^{\circ} \mathrm{C}$. Figure 1 shows the hatching process of a larva. The larvae moved spontaneously in a sinusoidal motion. Bacterial concentrations of $5 \times 10^{7} / \mathrm{mL}$ and beyond successfully induced hatching in $80 \%$ of the tests, at a rate ranging between 60 and $80 \%$. The hatching rate did not increase with $E$. coli concentrations over $5 \times 10^{7} / \mathrm{mL}$.

\section{Optimal culture conditions \\ Media}

In RPMI medium, 92.1\% ( $\pm 1.2 \%)$ of the larvae survived over 72 hours. The presence of $20 \mathrm{~g} / \mathrm{L}$ glucose or $5 \%$ FCS did not improve the survival rates compared to RPMI medium alone $(79.5 \% \pm 11.3 \%$ and $81.5 \% \pm 3.0 \%$, respectively after 72 hours). In MEM and DMEM larvae showed maximal survival rates of $23.8 \%$ and $6.5 \%$, respectively, after 24 hours. Similarly, larvae incubated in HBSS and in Medium 199 displayed poor survival rates after 72 hours (24.8\% and $15.1 \%$, respectively). The basic RPMI medium was used in all subsequent hatching and drug sensitivity tests.

\section{Temperature}

L1 survived for at least 72 hours at $37^{\circ} \mathrm{C}$ in RPMI medium. After 24 hours at room temperature all larvae were dead.

\section{Survival rates in RPMI medium}

Since RPMI medium was found to be the ideal medium for maintenance of $T$. muris L1 in vitro, behavior of L1 in this medium was studied in greater detail. Figure 2 shows the survival rates of L1 after 24, 48, 72, 96 and 120 hours in RPMI medium at $37^{\circ} \mathrm{C}$. Until 48 hours after hatching, the larvae showed survival rates over $80 \%$ $(84.3 \% \pm 4.0 \%$ after 24 hours and $88.8 \% \pm 1.8 \%$ after 48 hours). After 72 and 96 hours, survival rates decreased constantly until eventually falling below 50\% after 120 hours $(70.4 \% \pm 7.6 \%, 65.6 \% \pm 10.2 \%$ and $47.6 \% \pm 24.8 \%$, respectively).

\section{Motility assay}

As shown in Figure 3, the antiparasitic drug nitazoxanide as well as the anthelmintics oxantel pamoate and levamisole showed a much greater effect in vitro than the two standard drugs mebendazole and ivermectin. Drug concentrations of $50 \mu \mathrm{g} / \mathrm{mL}$ of mebendazole or ivermectin had no trichuricidal effect, as illustrated by the average survival rates of $93.3 \%( \pm 2.9 \%)$ and $93.1 \%$ $( \pm 1.3 \%)$, respectively, and did not differ significantly from the controls $(92.5 \% ; \pm 2.9 \%$; all $p>0.1)$. The same concentration of nitazoxanide, levamisole or oxantel pamoate was lethal in all three cases $(0 \%$ survival; all $\mathrm{p}<0.005)$. Nitazoxanide displayed a lower effect at concentrations of $10 \mu \mathrm{g} / \mathrm{mL}$ and below: $74.0 \%$ survival at $10 \mu \mathrm{g} / \mathrm{mL}( \pm 8.9 \%$; $\mathrm{p}<0.005)$ and $87.7 \%$ at $1 \mu \mathrm{g} / \mathrm{mL}( \pm 4.6 \% ; \mathrm{p}=0.046)$. Fifty and $10 \mu \mathrm{g} / \mathrm{mL}$ levamisole decreased survival by $>90 \%$ while $72.0 \%( \pm 6.3 \%)$ of the larvae survived after exposure to $1 \mu \mathrm{g} / \mathrm{mL}(\mathrm{p}<0.005)$. A concentration of $1 \mu \mathrm{g} / \mathrm{mL}$ oxantel pamoate killed almost all of the larvae (survival rate: $2.5 \%$; $\pm 2.9 \%)$. Survival rates of $51.9 \%( \pm 7.8 \%)$ and $78.6 \%$ $( \pm 11.7 \%)$ were determined for 0.1 and $0.01 \mu \mathrm{g} / \mathrm{mL}$ oxantel pamoate, respectively (not shown; all $\mathrm{p}<0.005$ ). Nitazoxanide, levamisole and oxantel pamoate displayed 


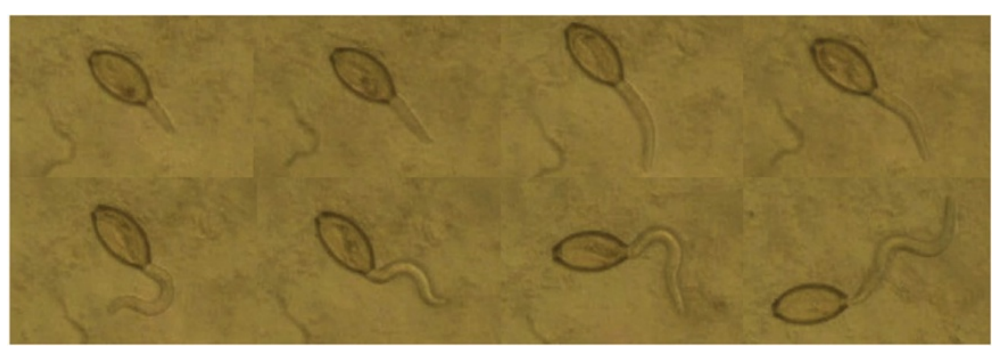

Figure 1 Hatching process of $T$. muris after exposure to $E$. coli (duration: approximately 2 minutes; magnification: 40x).

$\mathrm{IC}_{50}$ values of $4.4(\mathrm{r}: 0.86), 1.8(\mathrm{r}: 0.98)$ and $0.05 \mu \mathrm{g} / \mathrm{mL}$ (r: 0.97), respectively.

\section{Viability marker assays Resazurin assay}

After 12 hours of incubation, wells containing viable larvae displayed higher fluorescent emissions (2557 \pm 583.4 ) than wells containing larvae killed with $70 \%$ ethanol (1328 \pm 82.6$)$ (Figure 4). However, using nitazoxanide as test compound, a lack of correlation between the drug concentration and the signal measured was observed. For instance, wells containing parasites exposed to 1, 10 and $50 \mu \mathrm{g} / \mathrm{mL}$ had the following emission values: 1331 ( \pm 98.2 ), $1519( \pm 127.6)$ and $1944( \pm 435.4)$, respectively. These findings do not correlate with the efficacy of this drug observed in the motility assay (see motility assay section). In addition, wells containing higher drug concentrations also displayed higher fluorescent emissions than wells with lower drug concentrations and the strength of the signal varied between experiments.

\section{Feeding inhibition assay}

Evaluation with a fluorescence microscope demonstrated that $T$. muris L1 fail to ingest significant amounts of fluorescein-containing medium since no staining was observed in their gastrointestinal tract.

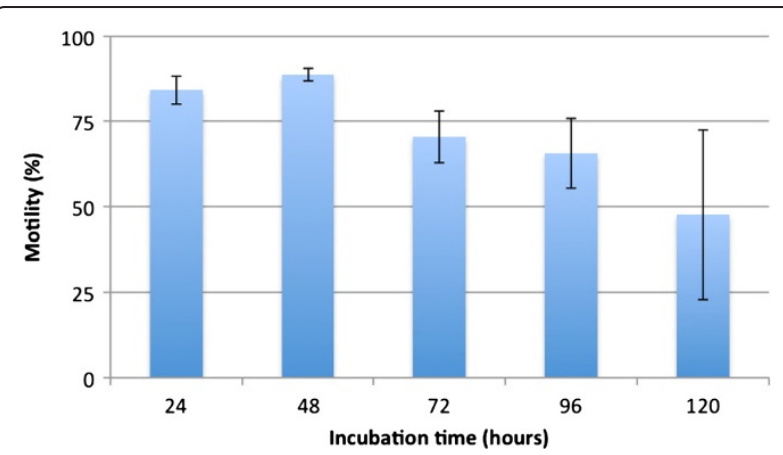

Figure 2 Survival rates (motility in percent) of $T$. muris L1 after

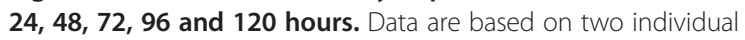
experiments, each performed in triplicate.

\section{LIVE/DEAD ${ }^{\circledR}$ cell viability assay}

Ethidium homodimer-1 (staining dead cells) did not show any significant fluorescent emission. The emission from the positive control wells containing motile L1 was higher than the emission of larvae exposed to oxantel pamoate. The microscopic analysis (using the texas red filter) revealed indistinguishable fluorescent emissions between viable and dead larvae.

In contrast to EthD-1, worms incubated with calcein AM showed a significant signal after 1 hour already. Figure 5 shows the background-adjusted emissions of viable $T$. muris L1 compared to dead controls after 4 hours of incubation with calcein AM. The measured signals failed to correlate with the number of parasites in each well. For instance, wells containing 25 viable L1 had a similar emission as wells containing 150 larvae (1260 \pm 285.8 compared to $1187 \pm 577.9)$. Emission values of wells containing dead parasites ranged from 29 ( \pm 75.4 ) for 50 worms to 807 ( \pm 197.6) for 150 worms. Furthermore, microscopic observation of the L1 staining was not found to be sufficient to discriminate live from dead larvae. In addition, drug-treated worms revealed higher signals than control worms. For instance, wells containing worms exposed to lethal concentrations of $50 \mu \mathrm{g} / \mathrm{mL}$ nitazoxanide and levamisole displayed fluorescent emissions

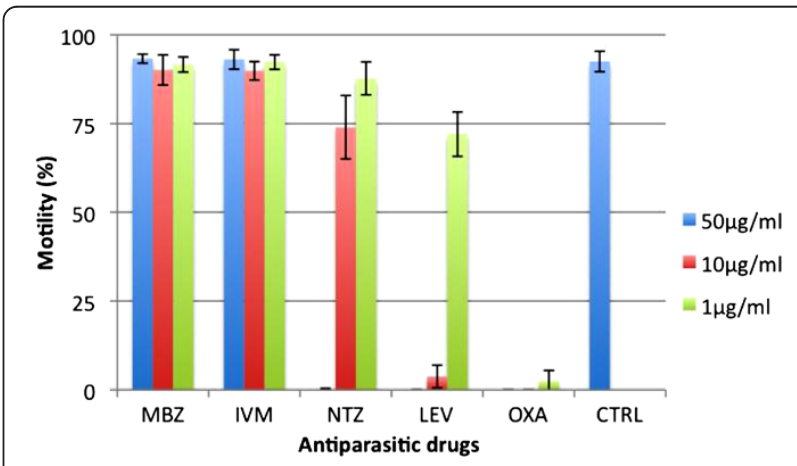

Figure 3 Survival rates (motility in percent) of $T$. muris L1 exposed to different drugs at concentrations of 1,10 and $\mathbf{5 0} \mathbf{~} \mathbf{g} / \mathbf{m L}$ for $\mathbf{2 4}$ hours. MBZ: mebendazole; IVM: ivermectin; NTZ: nitazoxanide; LEV: levamisole; OXA: oxantel pamoate; CTRL: control; 0.5\% DMSO. Data are based on three individual assays, each performed in quintuplicate. 


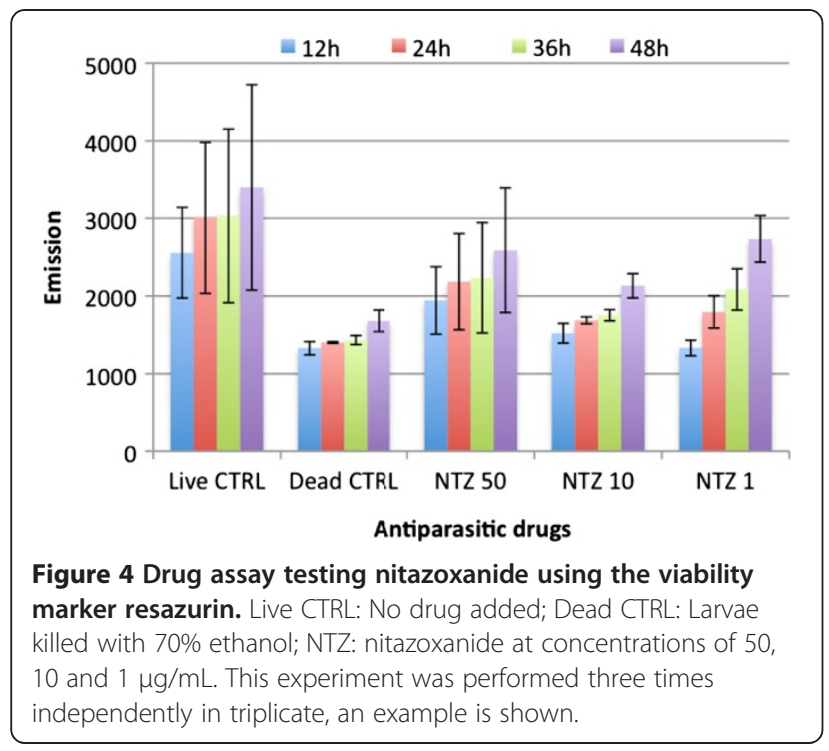

of $1505( \pm 149.2)$ and $1600( \pm 317.5)$, respectively, whereas only 513 ( \pm 528.0$)$ was measured for control worms. The signals emitted did not correlate with the motile activity of the larvae observed in the motility assay, where nitazoxanide and levamisole $(50 \mu \mathrm{g} / \mathrm{mL})$ reduced the viability of L1 by $100 \%$.

\section{Discussion}

Trichuriasis affects up to one billion people in the poorest regions of the world $[1,23]$. The drugs currently used against this parasite have a limited efficacy and have been used for decades [5,6]. Therefore, alternative treatments must be found. The current approach to identify potential new drug candidates relies essentially on the T. muris murine model. The in vitro assay of choice, the adult motility assay is expensive, labor-intensive, time-consuming and raises ethical questions. In this context, the objective of the present study was to develop a cost-effective and time-

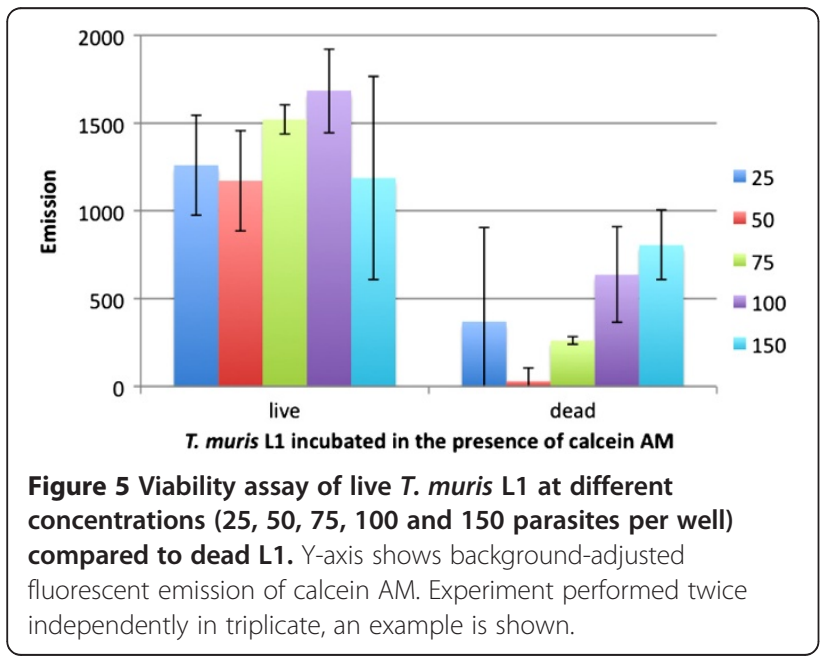

saving alternative assay. For this purpose, we developed a simple and reliable method to induce hatching of $T$. muris embryonated eggs exploiting findings from basic research [13]. The intestinal bacterium Escherichia coli was identified as optimal hatching stimulus while a series of potential triggers such as acid and intestinal enzymes were excluded.

The results obtained with the motility assay based on L1 correspond to findings observed with adult $T$. muris $[10,12,24]$. However, generally, L1 seem to be more sensitive to the drugs studied than older T. muris stages. For instance, Tritten et al. [12] determined the $\mathrm{IC}_{50}$ of levamisole to be $33.1 \mu \mathrm{g} / \mathrm{mL}$ for $\mathrm{L} 3$ and $16.5 \mu \mathrm{g} / \mathrm{mL}$ for adult worms whereas we calculated a value of $1.75 \mu \mathrm{g} / \mathrm{mL}$ for L1. An $\mathrm{IC}_{50}$ of $2.35 \mu \mathrm{g} / \mathrm{mL}$ was calculated for oxantel pamoate against L4 [24], whereas only $0.05 \mu \mathrm{g} / \mathrm{mL}$ was found for L1 in the present study. Nonetheless, the new assay might serve as a pre-screening tool and therefore complement assays using older larval stages and adult worms that necessitate sacrifice of the animal host. Thus, the number of necessary animal hosts can be reduced and the number of compounds to be tested can be increased.

Some characteristics of this new method are listed in Table 1 and compared to the assay for adult worms. The motility assay designed for adult T. muris was run over 72 hours and drug concentrations ranging from 50 to $200 \mu \mathrm{g} / \mathrm{mL}$ were used [10-12]. Since L1 were found to be more sensitive to the drugs tested, we performed the drug assay with lower drug concentrations $(0.01$ to $50 \mu \mathrm{g} /$ $\mathrm{mL}$ ) and microscopic assessment of parasite motility was undertaken after 24 hours. Assessing survival only once after a short period of time rendered the assay simpler and shorter. In addition, $T$. muris needs $>40$ days to develop to the adult stage, a time-frame that is saved while working with L1. Another advantage is that the results of the new assay can be considered more robust given that test worm sample sizes are larger. The assay can be

Table 1 Comparison between the drug sensitivity motility assay for $T$. muris L1 and adult parasites

\begin{tabular}{|c|c|c|}
\hline & $\begin{array}{l}\text { T. muris L1 } \\
\text { assay }\end{array}$ & $\begin{array}{c}\text { Adult } T \text {. muris } \\
\text { assay }\end{array}$ \\
\hline Duration of drug assay ${ }^{a}$ & 24 hours & 72 hours \\
\hline Number of parasites per well & 20 to 200 & 2 to 4 \\
\hline Dissection of animal host required & No & Yes \\
\hline Subjective analysis & Yes & Yes \\
\hline Viability marker alternative & No & $Y_{e s}^{b}$ \\
\hline Total operational hours & 3.5 hours $^{c}$ & 6.5 hours $^{d}$ \\
\hline $\begin{array}{l}\text { Applicability to high-throughput } \\
\text { screening }\end{array}$ & No & No \\
\hline
\end{tabular}

${ }^{a}$ : Time between start of the assay and its read-out. ${ }^{b}$ : Resazurin (Alamar Blue ${ }^{\circledR}$ ). ${ }^{c}$ : Including preparation and reading of the assay. ${ }^{d}$ : Including Infection, keeping and dissection of the animal host, collection of the parasites, preparation and reading of the assay. 
performed using basic laboratory equipment such as a light microscope and an incubator. Compared to the adult motility assay, the total time needed to conduct the assay ought to be as long as half and should not exceed 4 hours spread over 2 consecutive days (for an average of 10 to 15 compounds at a single concentration). Consequently, the total cost for the drug assay can be reduced by approximately $50 \%$. However, a notable drawback of this new method is that it relies on subjective microscopic analysis and includes a relatively time-consuming stimulation step. It is therefore not suitable for high-throughput drug screening.

Neither resazurin nor the LIVE/DEAD ${ }^{\circledR}$ viability/ cytotoxicity kit nor the feeding inhibition assay could provide consistent data about the condition of the larvae and drug effects on T. muris L1. Difficulties raised by the presence of the $E$. coli in the culture medium, could be solved to a certain extent by the use of the antibiotic ciprofloxacin $(500 \mu \mathrm{g} / \mathrm{mL})$. However, none of these viability and cytoxicity markers was able to detect a fluorescent signal that would reflect the parasites' viability and correlate with the findings of the motility assay.

In the resazurin assay, increased concentrations of nitazoxanide led to higher emission values, although not proportionally. This might suggest fluorescent properties of nitazoxanide or DMSO themselves, but this claim cannot be backed by published studies with adult $T$. muris [10]. The feeding inhibition assay, which already failed as a viability marker for A. ceylanicum L3 [15], cannot be used as a reliable viability marker for T. muris L1 either, since the larvae seem not to ingest significant amounts of fluorescein-albumin. T. muris L1 incubated together with ethidium homodimer-1 did not display significant fluorescent emissions. Calcein AM, although significant emission could be measured, did not enable discrimination between viable and drug-treated L1. No correlation was observed between the signal detected and the number of parasites per well. Hence, the Live/Dead ${ }^{\circledR}$ viability/cytotoxicity assay, successfully used in Leishmania research $[18,19]$, cannot be applied to $T$. muris L1 viability screening. As documented by Kaneshiro et al. [25], the combination of calcein AM and ethidium homodimer-1 shows strongly varying results in yeast and bacteria. Some of the proposed reasons for this are, possible lower esterase activity or the presence of thicker and less permeable outer structures than mammalian cells, for which the assay has been designed.

\section{Conclusion}

In conclusion, we have developed a reliable, costeffective, time- and labor-saving assay to evaluate drug sensitivity in T. muris L1. This assay, based on microscopic assessment of parasite motility, is now wellestablished at the Swiss TPH and, over the past months, several hundreds of new compounds have been tested against $T$. muris L1. The determination of an appropriate viability marker that would refine this new assay and enable high-throughput drug screening with an objective automated endpoint read-out necessitates further research.

\section{Competing interests}

The authors declare that they have no competing interests.

\section{Authors' contributions}

JK and LT designed the studies. DW carried out the experiments. DW, JK and LT wrote the manuscript. All authors read and approved the final version of the manuscript.

\section{Acknowledgement}

We thank Mireille Vargas and Roberto Adelfio for technical assistance. We are grateful to the Swiss National Science Foundation (project no. PPOOA3-

114941 and PPOOP3_135170 to JK) for financial support.

Received: 15 January 2013 Accepted: 15 February 2013

Published: 22 February 2013

\section{References}

1. Bethony J, Brooker S, Albonico M, Geiger SM, Loukas A, Diemert D, Hotez PJ: Soiltransmitted helminth infections: ascariasis, trichuriasis, and hookworm. Lancet 2006, 367:1521-1532.

2. Murray CJ, Vos T, Lozano R, Naghavi M, Flaxman AD, Michaud C, Ezzati M, Shibuya K, Salomon JA, Abdalla S, Aboyans V, Abraham J, Ackerman I, Aggarwal R, Ahn SY, Ali MK, Alvarado M, Anderson HR, Anderson LM, Andrews KG, Atkinson C, Baddour LM, Bahalim AN, Barker-Collo S, Barrero LH, Bartels DH, Basáñez MG, Baxter A, Bell ML, Benjamin El, et al: Disability-adjusted life years (DALYs) for 291 diseases and injuries in 21 regions, 1990-2010: a systematic analysis for the global burden of disease study 2010. Lancet 2012, 380:2197-223.

3. Stephenson LS, Holland CV, Cooper ES: The public health significance of Trichuris trichiura. Parasitology 2000, 121:S73-S95.

4. WHO: Preventive chemotherapy in human helminthiasis: coordinated use of anthelminthic drugs in control interventions: a manual for health professionals and programme managers. Geneva: WHO Press; 2006.

5. Keiser J, Utzinger J: Efficacy of current drugs against soil-transmitted helminth infections: systematic review and meta-analysis. JAMA 2008, 299:1937-1948.

6. Keiser J, Utzinger J: The drugs we have and the drugs we need against major helminth infections. Adv Parasitol 2010, 73:197-230.

7. Vercruysse J, Behnke JM, Albonico M, Ame SM, Angebault C, Bethony JM, Engels D, Guillard B, Hoa NTV, Kang G, Kattula D, Kotze AC, McCarthy JS, Mekonnen Z, Montresor A, Periago MV, Sumo L, Tchuem Tchuenté L-A, Thach DTC, Zeynudin A, Levecke B: Assessment of the anthelmintic efficacy of albendazole in school children in seven countries where soiltransmitted helminths are endemic. PLoS Negl Trop Dis 2011, 5:e948.

8. Keeling JE: Experimental trichuriasis. I. Antagonism between Trichuris muris and Aspiculuris tetraptera in the albino mouse. J Parasitol 1961, 47:641-646.

9. Keeling JE: Experimental trichuriasis. II. Antagonism between Trichuris muris and Aspiculuris tetraptera in the albino mouse. J Parasitol 1961, 47:647-651.

10. Silbereisen A, Tritten L, Keiser J: Exploration of novel in vitro assays to study drugs against Trichuris spp. J Microbiol Methods 2011, 87:169-175.

11. Tritten $L$, Silbereisen $A$, Keiser $\mathrm{J}$ : In vitro and in vivo efficacy of monepantel (AAD 1566) against laboratory models of human intestinal nematode infections. PLoS Negl Trop Dis 2011, 5:e1457.

12. Tritten $L$, Silbereisen $A$, Keiser J: Nitazoxanide: In vitro and in vivo drug effects against Trichuris muris and Ancylostoma ceylanicum, alone or in combination. Int J Parasitol: Drugs and Drug Resistance 2012, 2:98-105.

13. Hayes KS, Bancroft AJ, Goldrick M, Portsmouth C, Roberts IS, Grencis RK: Exploitation of the intestinal microflora by the parasitic nematode Trichuris muris. Science 2010, 328:1391-1394.

14. Räz B, Iten $M$, Grether-Bühler $Y$, Kaminsky R, Brun R: The Alamar Blue ${ }^{\circledR}$ assay to determine drug sensitivity of African trypanosomes (T.b. rhodiense and T.b. gambiense) in vitro. Acta Trop 1997, 68:139-147. 
15. Tritten L, Nwosu U, Vargas M, Keiser J: Comparison of novel and existing tools for studying drug sensitivity against the hookworm Ancylostoma ceylanicum in vitro. Parasitology 2012, 139:348-57.

16. Hawdon JM, Schad GA: Serum-stimulated feeding in vitro by third-stage larvae of the canine hookworm Ancylostoma caninum. J Parasitol 1990, 76:394-398.

17. Kopp SR, Coleman G, McCarthy J, Kotze AC: Application of in vitro anthelmintic sensitivity assays to canine parasitology: detecting resistance to pyrantel in Ancylostoma caninum. Vet Parasitol 2008, 152:284-293.

18. Essodaïgui M, Frézard F, Moreira ES, Dagger F, Garnier-Suillerot A: Energy-dependent efflux from Leishmania promastigotes of substrates of the mammalian multidrug resistance pumps. Mol Biochem Parasitol 1999, 100:73-84.

19. Wang Y, Chen Y, Xin L, Beverley SM, Carlsen ED, Popov V, Chang KP, Wang M, Soong L: Differential microbicidal effects of human histone proteins $\mathrm{H} 2 \mathrm{~A}$ and H2B on Leishmania promastigotes and amastigotes. Infect Immun 2011, 79:1124-1133.

20. McConnell EL, Basit AW, Murdan S: Measurements of rat and mouse gastrointestinal $\mathrm{pH}$, fluid and lymphoid tissue, and implications for in-vivo experiments. J Pharm Pharmacol 2008, 60:63-70.

21. Kotze AC, Clifford S, O'Grady J, Behnke JM, McCarthy JS: An in vitro larval motility assay to determine anthelminthic sensitivity for human hookworm and Strongyloides species. Am J Trop Med Hyg 2004, 71:608616.

22. Chou TC: Derivation and properties of michaelis-menten type and hill type equations for reference ligands. J Theor Biol 1976, 59:253-276.

23. Hotez PJ, Fenwick A, Savioli L, Molyneux DH: Rescuing the bottom billion through control of neglected tropical diseases. Lancet 2009, 373:1570-1575.

24. Keiser J, Tritten L, Silbereisen A, Speich B, Adelfio R, Vargas M: Activity of oxantel pamoate monotherapy and combination chemotherapy against Trichuris muris and hookworms: revival of an old drug. PLOS Negl Trop Dis 2013, in press; 10.1371/journal.pntd.0002119.

25. Kaneshiro ES, Wyder MA: Lipophosphoglycan antigen shedding by Leishmania donovani. J Eukaryot Microbiol 1993, 40:336-40.

doi:10.1186/1756-3305-6-42

Cite this article as: Wimmersberger et al.: Development of an in vitro drug sensitivity assay for Trichuris muris first-stage larvae. Parasites \& Vectors 2013 6:42.

\section{Submit your next manuscript to BioMed Central and take full advantage of:}

- Convenient online submission

- Thorough peer review

- No space constraints or color figure charges

- Immediate publication on acceptance

- Inclusion in PubMed, CAS, Scopus and Google Scholar

- Research which is freely available for redistribution 